\title{
Globalization and life lost due to tuberculosis: evidence from
}

\section{a multi-country study [version 1; peer review: 2 approved, 1}

\section{approved with reservations]}

\author{
Shyamkumar Sriram (i)1, Muayad Albadrani² \\ 1Johns Hopkins, Johns Hopkins Bloomberg School of Public Health, Baltimore, MD, 21205, USA \\ ${ }^{2}$ Taibah University, Taibah University, Medina, Medina, Saudi Arabia
}

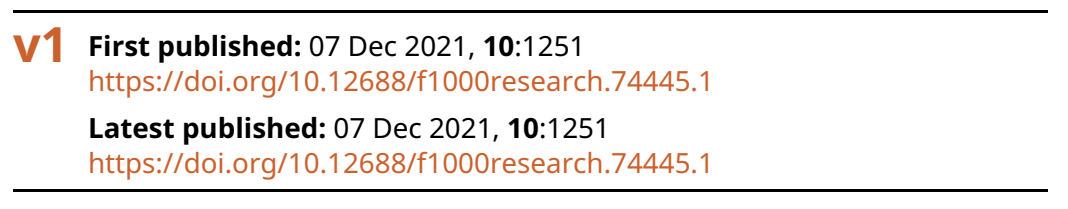

\section{Abstract}

Background: Tuberculosis affects around 30\% of the population of the world. Tuberculosis causes an increase in early mortality and thus has the potential to increase the number of years of life lost. Globalization directly or indirectly by affecting the factors that increase the susceptibility for tuberculosis infection has the potential to increase the spread and mortality due to tuberculosis. This study assessed the causal link between globalization and the years of life lost due to tuberculosis.

Methods: Data from the Demographic and Health Survey (DHS) and World Bank for 2004 and 2005 were used for a number of covariates and possible mediators. Data from the Institute of Health Metrics and Evaluation (IHME) were used for the outcome variable and important globalization indicators. The primary health outcome that was studied is tuberculosis and the measure that was used to quantify tuberculosis mortality is the years of life lost (YLL). Path analysis was used.

Results: The main independent variables of economic and social integration were not statistically significant. For every unit increase in the proportion of people that were using treated drinking water, there was a -0.0002 decrease in the YLL due to tuberculosis. For every unit increase in the proportion of people with earth floor, there was a 0.0002 units increase in YLL due to tuberculosis. For every unit increase in the proportion of people living using clean fuel, there was a 0.0004 decrease in the YLL due to tuberculosis.

Conclusions: Social and economic globalization have no effect on the years of life lost due to tuberculosis, highlighting that globalization actually does not contribute to tuberculosis mortality. However, improving other important determinants such as sanitation, providing safe drinking water and clean households will reduce the mortality due to tuberculosis, highlighting the need to invest in them.

\section{Open Peer Review \\ Approval Status ? 12 23 version 1 07 Dec 2021

$\begin{array}{cc}? & \checkmark \\ \text { view } & \text { view }\end{array}$ $\checkmark$ \\ 1. Setya Haksama ID, Universitas Airlangga, Surabaya, Indonesia \\ 2. Mohamed Adil AA (D), Vinayaga Mission Research Foundation, Chennai, India \\ 3. Arutselvi Devarajan (ID, M.V. Hospital for Diabetes and Prof. M. Viswanathan Diabetes Research Centre (WHO Collaborating Centre for Research, Education and Training in Diabetes) (IDF Centre for Excellence in Diabetes Care), Chennai, India} Any reports and responses or comments on the article can be found at the end of the article. 
Keywords

Globalization, tuberculosis, Years of Life Lost, mortality

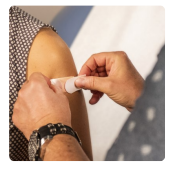

This article is included in the Sociology of

Health gateway.

Corresponding author: Shyamkumar Sriram (shyam.silverhawk@gmail.com)

Author roles: Sriram S: Conceptualization, Data Curation, Formal Analysis, Investigation, Methodology, Project Administration, Resources, Software, Supervision, Validation, Visualization, Writing - Original Draft Preparation, Writing - Review \& Editing; Albadrani M: Writing - Original Draft Preparation, Writing - Review \& Editing

Competing interests: No competing interests were disclosed.

Grant information: The author(s) declared that no grants were involved in supporting this work.

Copyright: ( 2021 Sriram S and Albadrani M. This is an open access article distributed under the terms of the Creative Commons Attribution License, which permits unrestricted use, distribution, and reproduction in any medium, provided the original work is properly cited.

How to cite this article: Sriram S and Albadrani M. Globalization and life lost due to tuberculosis: evidence from a multi-country study [version 1; peer review: 2 approved, 1 approved with reservations] F1000Research 2021, 10:1251

https://doi.org/10.12688/f1000research.74445.1

First published: 07 Dec 2021, 10:1251 https://doi.org/10.12688/f1000research.74445.1 


\section{Background}

Tuberculosis (TB) is a disease that is caused by the bacteria, Mycobacterium tuberculosis. Tuberculosis affects around $30 \%$ of the population of the world. ${ }^{1}$ Incidence of tuberculosis is around nine million new cases every year. ${ }^{1}$ Studies globally show that tuberculosis causes an increase in early mortality and thus has the potential to increase the number of years of life lost. Annual mortality due to tuberculosis is around one and half million. ${ }^{1}$ The transmission of the disease is predominantly airborne in most of the cases and exposure to the disease agent is needed for any person to develop the infection or the disease. ${ }^{2}$ However, there are many individual, household and environmental factors that increase the susceptibility of the individual to develop the infection. ${ }^{3}$ Globally, the disease which had been controlled over the past two decades has shown to be reemerging in a number of countries, especially in the developing world. ${ }^{4-6}$ Globalization, specifically the negative effects and externalities of globalization have shown to increase the spread of a number of infectious diseases. Some studies have explored the effect of globalization on tuberculosis spread and found that globalization increases the spread of tuberculosis, especially in countries with poverty and poor health systems. ${ }^{7}$ Evidence also shows that globalization has also been found to have a negative effect on poverty specifically by increasing poverty for certain underprivileged sections of the population. ${ }^{8}$ Some of the factors which increase the susceptibility of an individual to develop tuberculosis such as living in over-crowded houses, having poor sanitation facilities, poor housing conditions, and the consumption of unsafe water are all directly related to the availability of household resources and poverty. ${ }^{7,9}$ Thus, globalization, by directly or indirectly affecting the factors that increase the susceptibility for tuberculosis infection, has the potential to increase the spread and mortality due to tuberculosis and in turn increasing the number of years of life lost.

There are many aspects and components of globalization. There is a constant movement of people across the globe (social globalization) and the flow of capital across countries (economic globalization). ${ }^{10}$ Both social and economic components of globalization have the potential to increase the spread of tuberculosis either directly by increased movement and contact of people or by causing changes in the economy which affects the factors that increase the susceptibility to develop tuberculosis. Evidence shows that in some populations globalization increased their economic conditions, while in others globalization reduced their economic status leading to an increase in poverty, unemployment, and unsanitary living conditions. ${ }^{11,12}$ There is only scarce literature linking globalization and tuberculosis. ${ }^{2,3,13-15}$ Current available literature on globalization and tuberculosis is able to only correlate the increase in globalization over the past decade and the increase in burden of tuberculosis in specific countries of the world. These studies failed to prove conclusively that globalization by itself leads to changes in the spread of tuberculosis, although some patterns were observed. Also, the studies on globalization are more prone to confounding because of many unforeseen factors. Currently evidence on the effect of globalization on the mortality and years of life lost due to tuberculosis is lacking. This study aims to address this gap in literature through the empirical use of secondary data that is available from several international agencies to quantify and assess the causal link between globalization and the years of life lost due to tuberculosis.

\section{Methods}

Ethical approval

The secondary datasets used in this study are available in the public domain after all individual level identification variables were removed. It was not possible to identify the residence of any of the households as well. Therefore, ethical approval was not required for the study.

\section{Consent for participation/publication \\ Not applicable}

\section{Study population}

This study examined the population globally representing 40 countries from every continent and every WHO region in the world. The specific age-group that was studied is the age group of 15 years and above. The primary health outcome that was studied is tuberculosis and the measure that was used to quantify tuberculosis mortality was the years of life lost (YLL). YLL for TB for 2010 was used in the study. Tuberculosis has an incubation period of a few months to about two years from exposure to the development of disease. The independent variables was studied for 2005. This five year gap not only provided the time for the disease to develop from exposure but also the period when there was a shift in the independent variables and the impact of those variables on the population health outcome, TB.

\section{Data}

The DHS Program STATcompiler was used to extract the data from the DHS and World Bank. Data on the proportion of households with poor household sanitation, open defecation, safe drinking water, smoking cigarettes, literacy, type of cooking fuel, BCG vaccination, overcrowding, and unclean floors were obtained from the Demographic and Health Survey (DHS) for years 2004 and 2005. Data on the Poverty headcount and GNI per capita were obtained from the World 
Bank for the years 2004 and 2005. Data were assessed for a number of covariates and possible mediators. Data from the Institute of Health Metrics and Evaluation (IHME) were used for the outcome variable (Years of Life Lost due to Tuberculosis) and important globalization indicators (Economic globalization index and Social globalization index) for the year 2010 were used. The time-period for tuberculosis development varies. Tuberculosis has an incubation period of a few months to about two years from exposure to the development of disease. The effect of the key independent variable and other variables on the development of tuberculosis can be studied only if they are examined for at least three to five years before 2010 (the year when tuberculosis outcome is studied).

\section{Analytic framework}

\begin{tabular}{|l|}
\hline Key independent variable(s): \\
\hline Economic globalization \\
index variable and Social \\
globalization index variable
\end{tabular}

\begin{tabular}{|l|l|}
\hline \begin{tabular}{l} 
Other variables: \\
\hline $\begin{array}{l}\text { Over-crowding, Indoor air } \\
\text { pollution, Type of housing, } \\
\text { Sanitation, safe water }\end{array}$
\end{tabular} & $\begin{array}{l}\text { Population health outcome: } \\
\text { Years of Life Lost due to } \\
\text { Tuberculosis }\end{array}$ \\
\hline
\end{tabular}

\section{Variables of interest/key variables}

The key dependent variable was the Years of Life Lost (YLL) due to tuberculosis in 40 countries. The main independent variables included the variables of globalization index namely the variable for economic integration and social integration. The possible mediators included the variables for sanitation, clean drinking water, indoor air pollution (clean cooking fuel), and over-crowding.

\section{Statistical analysis}

Descriptive analysis was be used to describe the trends in the data. Path analysis was used to study both the effect of the various independent variables on the outcome variable and also to study the effect of the globalization index variables (economic and social integration) on the mediator variables. Path analysis helped in understanding the directed dependencies among the different variables. Statistical software STATA (version 17) was be used for the data analysis.

\section{Results}

\section{Descriptive statistics}

The average overall proportion of population having improved household sanitation facility was $49.10 \%$ as shown in Table 1. Table 2 shows the descriptive statistics by country. In Jordan (99.6\%), the highest proportion of population had improved sanitation facility while Madagascar (4.2\%) had the lowest sanitation facility. The average overall proportion of people living in households treating drinking water was $66.77 \%$. Egypt $(95.5 \%)$ had the highest proportion of population living in households that were treating drinking water. The average overall proportion of people using clean fuel for cooking was $25.44 \%$. The proportion varied from $99.9 \%$ in Jordan to none of the population having clean cooking fuel in Sierra Leone. The average overall proportion of population in households with seven or more persons sleeping per room

Table 1. Descriptive statistics for whole sample.

\begin{tabular}{|l|l|l|}
\hline Variables & Definition & Mean (SD) \\
\hline Prop_Pop_Impro_Sanitation & $\begin{array}{l}\text { Proportion of population having improved household } \\
\text { sanitation facility }\end{array}$ & $49.10(27.60)$ \\
\hline Water_treated & $\begin{array}{l}\text { Proportion of people living in households treating drinking } \\
\text { water }\end{array}$ & $66.77(24.72)$ \\
\hline CookingFuel & Proportion of people using clean fuel for cooking & $25.44(28.78)$ \\
\hline rooms_7more & $\begin{array}{l}\text { Proportion of population in households with 7+ persons } \\
\text { sleeping per room }\end{array}$ & $2.50(1.66)$ \\
\hline Earth_sandfloors & Proportion of people living in houses with earth/sand floors & $37.70(25.33)$ \\
\hline YLL Tuberculosis & Average years of life lost due to Tuberculosis & $0.0323(0.0314)$ \\
\hline Economic integration & Economic integration & $2.97(1.15)$ \\
\hline Social integration & Social integration & $1.09(1.03)$ \\
\hline
\end{tabular}


Table 2. Descriptive statistics by country.

\begin{tabular}{|c|c|c|c|c|c|c|c|}
\hline S. No & Country & YLL-TB & $\begin{array}{l}\text { Economic } \\
\text { integration }\end{array}$ & $\begin{array}{l}\text { Social } \\
\text { integration }\end{array}$ & Sanitation & $\begin{array}{l}\text { Treated } \\
\text { water }\end{array}$ & $\begin{array}{l}\text { Sand } \\
\text { floors }\end{array}$ \\
\hline 1 & Bangladesh & 0.0424 & 2.56 & 1.03 & 24.30 & 92.50 & 79.60 \\
\hline 2 & Benin & 0.0310 & 0.59 & 0.81 & 17.10 & 93.80 & 41.00 \\
\hline 3 & Bolivia & 0.0323 & 4.32 & 1.10 & 11.30 & 14.60 & 29.10 \\
\hline 4 & Brazil & 0.0051 & 3.50 & 1.54 & 49.40 & 66.50 & 6.40 \\
\hline 5 & Cameroon & 0.0202 & 2.50 & 0.99 & 35.00 & 11.30 & 51.10 \\
\hline 6 & CAR & 0.0423 & 2.02 & 0.37 & 14.40 & 23.80 & 81.60 \\
\hline 7 & Colombia & 0.0054 & 3.61 & 1.39 & 87.20 & 80.90 & 8.50 \\
\hline 8 & DRC & 0.0652 & 2.24 & 0.21 & 40.10 & 71.50 & 74.70 \\
\hline 9 & Egypt & 0.0027 & 3.41 & 1.32 & 99.50 & 95.50 & 11.90 \\
\hline 10 & Gabon & 0.0185 & 2.62 & 0.31 & 46.60 & 32.30 & 21.40 \\
\hline 11 & Ghana & 0.0217 & 2.78 & 1.40 & 66.40 & 89.80 & 15.10 \\
\hline 12 & Guatemala & 0.0074 & 3.89 & 1.45 & 41.20 & 56.40 & 41.70 \\
\hline 13 & Guyana & 0.0103 & 3.53 & 0.72 & 92.40 & 51.90 & 2.90 \\
\hline 14 & Haiti & 0.0125 & 0.34 & 1.07 & 29.80 & 66.90 & 38.50 \\
\hline 15 & Honduras & 0.0059 & 3.85 & 1.20 & 64.00 & 55.00 & 26.40 \\
\hline 16 & India & 0.0527 & 2.26 & 1.01 & 39.70 & 66.80 & 33.10 \\
\hline 17 & Indonesia & 0.1273 & 3.85 & 0.96 & 52.00 & 6.30 & 11.40 \\
\hline 18 & Jordan & 0.0020 & 3.93 & 1.00 & 99.60 & 78.50 & 0.10 \\
\hline 19 & Kenya & 0.0393 & 3.33 & 0.81 & 44.60 & 56.30 & 37.70 \\
\hline 20 & Madagascar & 0.0275 & 1.56 & 0.76 & 4.20 & 49.30 & 15.10 \\
\hline 21 & Malawi & 0.0356 & 2.61 & 0.88 & 4.80 & 34.90 & 77.60 \\
\hline 22 & Mali & 0.0390 & 2.00 & 0.51 & 21.30 & 66.10 & 58.10 \\
\hline 23 & Mauritius & 0.0275 & 3.89 & 1.70 & 22.40 & 32.50 & 62.70 \\
\hline 24 & Namibia & 0.0451 & 2.99 & 1.22 & 42.10 & 90.40 & 46.40 \\
\hline 25 & Nepal & 0.0658 & 2.61 & 0.03 & 36.50 & 86.50 & 69.30 \\
\hline 26 & Nicaragua & 0.0129 & 4.66 & 1.18 & 33.70 & 34.30 & 45.50 \\
\hline 27 & Niger & 0.0493 & 1.86 & 0.70 & 9.20 & 69.00 & 87.20 \\
\hline 28 & Nigeria & 0.0317 & 2.72 & 0.16 & 53.00 & 84.30 & 35.90 \\
\hline 29 & Pakistan & 0.0528 & 1.58 & 1.12 & 53.20 & 90.00 & 49.60 \\
\hline 30 & Peru & 0.0230 & 4.22 & 1.11 & 67.00 & 12.60 & 40.10 \\
\hline 31 & Philippines & 0.0490 & 3.60 & 1.16 & 86.30 & 69.10 & 8.60 \\
\hline 32 & Rwanda & 0.0592 & 1.33 & 0.33 & 55.60 & 56.10 & 83.20 \\
\hline 33 & Senegal & 0.0384 & 3.00 & 1.02 & 80.50 & 35.60 & 26.10 \\
\hline 34 & Sierra Leone & 0.0443 & 2.10 & 0.13 & 44.10 & 89.00 & 56.30 \\
\hline 35 & Togo & 0.0327 & 0.98 & 0.87 & 29.30 & 37.30 & 27.80 \\
\hline 36 & Turkey & 0.0040 & 4.04 & 1.65 & 99.10 & 23.50 & 3.80 \\
\hline 37 & Uganda & 0.0582 & 4.92 & 6.90 & 24.30 & 60.70 & 39.10 \\
\hline 38 & Ukraine & 0.0162 & 3.77 & 0.74 & 98.50 & 15.80 & 0.20 \\
\hline 39 & Zambia & 0.0376 & 4.62 & 1.19 & 37.40 & 63.20 & 59.30 \\
\hline 40 & Zimbabwe & 0.0460 & 4.62 & 1.19 & 56.40 & 25.10 & 16.70 \\
\hline
\end{tabular}


Table 3. Path regression analysis on the factors affecting Years of Life Lost due to TB.

\begin{tabular}{|l|l|l|l|}
\hline Characteristics & Coefficient & $\begin{array}{l}\text { Standard } \\
\text { error }\end{array}$ & P value \\
\hline Mean years of life lost due to TB & & & \\
\hline Economic integration & 0.0035789 & 0.0019183 & 0.06 \\
\hline Social integration & 0.0004549 & 0.0013553 & 0.73 \\
\hline Proportion of population having improved household sanitation facility & 0.0001243 & 0.0001231 & 0.31 \\
\hline Proportion of people living in households treating drinking water & -0.0002498 & 0.0000757 & $<0.01$ \\
\hline Proportion of people using clean fuel for cooking & -0.0004893 & 0.0000879 & $<0.01$ \\
\hline Proportion of people living in houses with earth/sand floors & 0.0002075 & 0.0000905 & 0.02 \\
\hline Constant & 0.040401 & 0.0074816 & $<0.01$ \\
\hline Proportion of population having improved household sanitation facility & 14.48399 & 0.7772967 & $<0.01$ \\
\hline Economic integration & -8.025419 & 0.7054411 & $<0.01$ \\
\hline Social integration & 14.89532 & 2.140847 & $<0.01$ \\
\hline Constant & & -8.65949 & 0.7769014 \\
\hline Proportion of people living in households treating drinking water & $<0.01$ \\
\hline Economic integration & 1.54382 & 0.7050823 & 0.02 \\
\hline Social integration & 90.4312 & 2.139758 & $<0.01$ \\
\hline Constant & & -5.542206 & 0.8563732 \\
\hline Proportion of people living in houses with earth/sand floors & 0.9719376 & 0.7772075 & 0.21 \\
\hline Economic integration & 52.56139 & 2.358641 & $<0.01$ \\
\hline Social integration & & $<01$ \\
\hline Constant & & \\
\hline
\end{tabular}

was $2.50 \%$. India had the highest proportion of overcrowding in houses, while Indonesia had the lowest overcrowding among the list of selected countries. The average overall proportion of people living in houses with earth/sand floors was $37.70 \%$. Niger around $87.2 \%$ of the houses having sand floors, while Jordan had only $0.1 \%$ of the houses with sand floors. The average years of life lost due to tuberculosis was 0.0323 years with Indonesia facing the highest years of life lost due to TB, while counties like Guyana, Kenya, Peru facing the lowest years of life lost due to TB. The average economic integration score was 2.97. Uganda (4.92) had the highest economic integration, while Haiti (0.34) had the lowest economic integration. The average social integration score was 1.09. Uganda (6.90) had the highest social integration, while Nepal (0.03) had the lowest social integration.

\section{Regression analysis}

A path analysis model with an OLS regression component was used to study the effect of the main independent variables of globalization (economic and social globalization) and other covariates and potential mediating variables on the outcome variable of years of life lost due to tuberculosis. The results of the regression analysis are shown in Table 3 . The main independent variables of economic and social integration were not statistically significant showing that they have no significant effect on the years of life lost (YLL) due to tuberculosis. Other possible mediator variables such as proportion of population having improved household sanitation facility did not have any statistically significant effect on the YLL due to tuberculosis. The variables of proportion of people living in households treating drinking water, the variable proportion of people using clean fuel for cooking and the proportion of people living in houses with earth/sand floors were statistically significant. For every unit increase in the proportion of people living in households that were using treated drinking water, there was a -0.0002 decrease in the YLL due to tuberculosis. For every unit increase in the proportion of people living in houses with earth or sand floor, there was 0.0002 units increase in the YLL due to tuberculosis. For every unit increase in the proportion of people living using clean fuel for cooking, there was a 0.0004 decrease in the YLL due to tuberculosis. The results of the path regression analysis show that economic integration had a positive impact on sanitation and a negative effect on water treatment and the proportion of households with sand floors. Social integration on the other hand seemed to have a negative impact on sanitation, while having a positive effect on the proportion of households that were treating water. 


\section{Discussion}

The results of the study show that there is no effect of social and economic globalization on the years of life lost due to tuberculosis. Literature shows that there are no other studies that have explored this specific relationship of globalization in the context of years of life lost due to tuberculosis. However, there are other studies which have explored similar relationships between globalization and other diseases and outcome measures. ${ }^{10}$ For example, a study analyzed the effect of social and economic globalization on obesity and overweight and concluded that the different components of globalization increased the propensity of the individual to become overweight, especially among women. ${ }^{10}$ However, in this research, no such relationships could be established in the context of globalization and tuberculosis. This study shows that sanitary conditions in the household are not statistically associated with the years of life lost due to tuberculosis. However, other studies have shown that living in a household with good sanitary conditions not only decreased the propensity of developing tuberculosis but also reduced the mortality due to tuberculosis. ${ }^{9,16,17}$ This research also shows that people who are living in households that are consuming treated drinking water had lower years of life lost due to tuberculosis. This is consistent with findings in literature which show that households that consume boiled and treated safe drinking water had lower risk of developing tuberculosis and also associated lower mortality due to tuberculosis. ${ }^{16,18-20}$ The people who live in houses that have dusty environment with earth or sand floors have been found to have higher mortality due to tuberculosis and thus higher years of lost. This aligns with the findings from literature which show that living in an unclean and dusty environment increases the susceptibility of developing tuberculosis and also increasing the progression and severity of the disease leading to increased mortality. ${ }^{16,21}$ Houses with dirty floors and dust serve as a vehicle for transmission for tuberculosis, especially if the patient removes saliva or phlegm on the floor of the house. In addition, evidence shows that there is a higher probability of reactivation of tuberculosis infection among individuals who live in insanitary and unclean household conditions. ${ }^{22}$ Indoor air pollution has shown to be an important predisposing and enabling factor for tuberculosis. ${ }^{23,24}$ Usage of unclean cooking fuel which is rampant in developing countries is one of the important causes globally for indoor air pollution. ${ }^{25,26}$ This study also supports this finding. Households that use clean cooking fuel has been found to have lower years of life lost due to tuberculosis compared to households that used unclean fuel for cooking. This study shows that economic integration has a positive effect on sanitation. There is no specific literature which relates economic globalization with sanitation however some evidence shows that globalization increases household wealth in some populations, and this is directly proportional to increased levels of sanitation. ${ }^{15}$ The negative relationship between economic globalization and poor access to safe drinking water could not be supported by any evidence from literature. In this study, social integration has a negative impact on household sanitation. Although no specific evidence linking social globalization and household sanitation could be found, some evidence from literature show that globalization has the potential to push certain groups of the population into poverty which reduces their financial capacity to maintain proper hygiene and sanitation in the household. ${ }^{8,11,12,27-30}$

\section{Conclusions}

This study provides vital analysis into the different aspects of globalization and their effect on tuberculosis spread in many countries across different continents. This will help in global policy making regarding infectious disease spread. Social and economic globalization have no effect on the years of life lost due to tuberculosis, highlighting that globalization actually does not contribute to tuberculosis mortality. This will help in clearing the common myth that globalization is one of the main reasons for tuberculosis spread across national borders. However, improving other important determinants such as sanitation, providing safe drinking water and clean households will reduce the mortality due to tuberculosis, highlighting the need to invest in them. In conclusion this research could not find any relationship between globalization and the years of life lost due to tuberculosis. More research is needed to understand the mechanism in which social and economic globalization influence tuberculosis specifically the years of life lost due to tuberculosis.

\section{Strengths and limitations}

The main strengths of this study include the use of secondary data from multiple international agencies which have a reliable and robust method of data collection and adequate data quality control mechanisms in place. The study also considers the adequate time lag between the independent variables (exposures) and the health outcome to develop. The main limitations of this study also arise from the use of secondary data. Any study that uses secondary data suffers from this limitation, i.e., the study becomes limited by the data collected and survey methodology used. The contents and the questions asked in the survey limits the extent of our research questions to fit the data that is available for analysis. Also, cross-sectional data has been used for the study and thus no follow-up over time has been done. This cross-sectional nature of the data creates an important limitation that it allows to study only the association and not actual causation of mortality due to tuberculosis because of globalization to be established. Cross-sectional data cannot infer causal association mainly because temporality is not known and thus cannot assess the change in outcomes over time. The limitations of the model include the use of path regression analysis. Although the OLS component of the path regression model can be used to establish association between the outcome variable and the various independent 
variables, but path analysis is not a causality test so the causal associations of the potential mediating variables cannot be ascertained. $^{31}$

\section{Data availability}

The DHS Program STATcompiler was used to extract the data from the DHS and World Bank. Data on the proportion of households with poor household sanitation, open defecation, safe drinking water, smoking cigarettes, literacy, type of cooking fuel, BCG vaccination, overcrowding, and unclean floors were obtained from the Demographic and Health Survey (DHS) for years 2004 and 2005. Access to the dataset requires registration and is granted only for legitimate research purposes. A guide for how to apply for dataset access is available at: https://dhsprogram.com/data/AccessInstructions.cfm. Data on the Poverty headcount and GNI per capita were obtained from the World Bank for the years 2004 and 2005. World Bank data is available for open access. Poverty headcount data is available at: https://data. worldbank.org/indicator/SI.POV.DDAY and GNI per capita is available at: https://data.worldbank.org/indicator/NY. GNP.PCAP.CD. Data from the Institute of Health Metrics and Evaluation (IHME) were used for the outcome variable (Years of Life Lost due to Tuberculosis) and important globalization indicators (Economic integration and integration) for the year 2010 was used. Data can be obtained from the IHME website: http://www.healthdata.org/.

\section{References}

1. World Health Organization: Global Tuberculosis Report 2020. Accessed on 15 May 2021.

Reference Source

2. Selgelid MJ: Ethics, Tuberculosis and Globalization. Public Health Ethics. 2008; 1(1): 10-20. Publisher Full Text

3. Fanning EA: Globalization of tuberculosis. CMAJ. 1998; 158(5): 611-612.

PubMed Abstract

4. Porter JD, McAdam KP: The re-emergence of tuberculosis. Annu. Rev. Public Health. 1994; 15: 303-323. Publisher Full Text

5. Borgdorff MW, van Soolingen D: The re-emergence of tuberculosis: what have we learnt from molecular epidemiology?. Clin. Microbiol. Infect. 2013; 19(10): 889-901. PubMed Abstract | Publisher Full Text

6. Brennan PJ: Tuberculosis in the context of emerging and reemerging diseases. FEMS Immunol. Med. Microbiol. 1997; 18(4): 263-269.

PubMed Abstract | Publisher Full Text

7. Marais BJ, Hesseling AC, Cotton MF: Poverty and tuberculosis: is it truly a simple inverse linear correlation?. Eur. Respir.J. 2009; 33(4): 943-944.

PubMed Abstract | Publisher Full Text

8. Rahim HL, Abidin ZZ, Ping SD, et al.: Globalization and its Effect on World Poverty and Inequality. Global Journal of Management and Business. 2014; 1(2): 8-13.

9. Singh SK, Kashyap GC, Puri P: Potential effect of household environment on prevalence of tuberculosis in India: evidence from the recent round of a cross-sectional survey. BMC Pulm. Med. 2018; 18(1): 66 . PubMed Abstract | Publisher Full Text

10. Goryakin Y, Lobstein T, James WPT, et al.: The impact of economic, political and social globalization on overweight and obesity in the $\mathbf{5 6}$ low and middle income countries. Soc. Sci. Med. 1982; 133(133): 67-76 Publisher Full Text

11. Wade RH: Is Globalization Reducing Poverty and Inequality?. World Dev. 2004; 32(4): 567-589. Publisher Full Text

12. Basu K: Globalization, poverty, and inequality: What is the relationship? What can be done?. World Dev. 2006; 34(8): 1361-1373. Publisher Full Text

13. Saleh J-E: Globalization and the Spread of Multi-Drug Resistant Tuberculosis. Journal of Health, Medicine and Nursing. 2015; 18: 20-24.

14. Girardi E, Sañé Schepisi M, Goletti D, et al.: The global dynamics of diabetes and tuberculosis: the impact of migration and policy implications. Int. J. Infect. Dis. 2017; 56 45-53.

PubMed Abstract | Publisher Full Text
15. Labonté R, Mohindra K, Schrecker T: The Growing Impact of Globalization for Health and Public Health Practice. Annu. Rev. Public Health. 2011; 32(1): 263-283. Publisher Full Text

16. Cardoso BA, Fonseca FO, Moraes AHAN, et al.: Environmental aspects related to tuberculosis and intestinal parasites in a lowincome community of the Brazilian Amazon. Rev. Inst. Med. Trop. Sao Paulo. 2017; 59: e57-e.

Publisher Full Text

17. World Health Organization: Global tuberculosis report 2016. Geneva: WHO; 2016

18. Clasen $T$, Pruss-Ustun $A$, Mathers $C D$, et al.: Estimating the impact of unsafe water, sanitation and hygiene on the global burden of disease: evolving and alternative methods. Tropical Med. Int. Health. 2014; 19(8): 884-893. PubMed Abstract | Publisher Full Text

19. Greenberg AE, Kupka E: Tuberculosis Transmission by Waste Waters: A Review. Sewage Ind. Waste. 1957; 29(5): 524-537.

20. Vaerewijck MJM, Huys G, Palomino JC, et al.: Mycobacteria in drinking water distribution systems: ecology and significance for human health. FEMS Microbiol. Rev. 2005; 29(5): 911-934. PubMed Abstract | Publisher Full Text

21. Aditama W, Sitepu F, Saputra R: Relationship between Physical Condition of House Environment and the Incidence of Pulmonary Tuberculosis, Aceh, Indonesia. 2019; 227.

22. Cardona P-J: Reactivation or reinfection in adult tuberculosis: Is that the question?. International Journal of Mycobacteriology. 2016; 5(4): 400-407. PubMed Abstract | Publisher Full Text

23. Patel V, Foster A, Salem A, et al.: Long-term exposure to indoor air pollution and risk of tuberculosis. Indoor Air. 2021; 31(3): 628-638. PubMed Abstract | Publisher Full Text

24. Schweitzer MD, Patel V, Mirsaeidi M, et al.: Does Indoor Air Pollution Enhance the Risk of Tuberculosis Infection? B63 LATENT TUBERCULOSIS INFECTION AND EPIDEMIOLOGY OF TUBERCULOSIS DISEASE. American Thoracic Society International Conference Abstracts: American Thoracic Society. 2017; p. A3983-A.

25. Faizan MA, Thakur R: Association Between Solid Cooking Fuels and Respiratory Disease Across Socio-Demographic Groups in India. 2019; 9(23): 190911.

26. Bates MN, Pope K, Sijali TR, et al.: Household fuel use and pulmonary tuberculosis in western Nepal: A case-control study. Environ. Res. 2019; 168: 193-205. PubMed Abstract | Publisher Full Text

27. Njuguna J: Progress in sanitation among poor households in Kenya: evidence from demographic and health surveys. $B M C$ Public Health. 2019; 19(1): 135. PubMed Abstract | Publisher Full Text

28. Dehury B, Mohanty SK: Multidimensional poverty, household environment and short-term morbidity in India. Genus. 2017; 73(1): 3.

PubMed Abstract | Publisher Full Text 
29. Mariwah S, Amo-Adjei J, Anima P: What has poverty got to do with it? Analysis of household access to improved sanitation in Ghana. Journal of Water, Sanitation and Hygiene for Development 2017; 7(1): 129-139.

Publisher Full Text

30. Gizaw Z, Addisu A: Evidence of Households' Water, Sanitation, and Hygiene (WASH) Performance Improvement Following a
WASH Education Program in Rural Dembiya, Northwest Ethiopia. Environ. Health Insights. 2020; 14: 117863022090310. Publisher Full Text

31. Heise DR: Problems in Path Analysis and Causal Inference. Sociol. Methodol. 1969; 1: 38-73.

Publisher Full Text 


\section{Open Peer Review}

\section{Current Peer Review Status:}

\section{Version 1}

Reviewer Report 18 January 2022

https://doi.org/10.5256/f1000research.78203.r119880

(C) 2022 Devarajan A. This is an open access peer review report distributed under the terms of the Creative Commons Attribution License, which permits unrestricted use, distribution, and reproduction in any medium, provided the original work is properly cited.

\section{Arutselvi Devarajan}

Department of Epidemiology, M.V. Hospital for Diabetes and Prof. M. Viswanathan Diabetes Research Centre (WHO Collaborating Centre for Research, Education and Training in Diabetes) (IDF Centre for Excellence in Diabetes Care), Chennai, India

This paper explored an important aspect of the public health issue of TB and its association with globalization.

I have some suggestions for the authors:

The nature of data was cited as the reason for not being able to completely explain the causal link, I suggest the authors mention only association (as the data may exhibit some correlation but not causation) instead of the "causal link" in the objective.

Although the current introduction is good, it would be better if there are more indirect indicators or covariates that affect tuberculosis incidence.

The methods section is good and elaborate. The aspects of globalization - economic and social, and other aspects of globalization could also be considered in this research or for future research.

The main outcome variable is Years of Life Lost due to tuberculosis. It would be much better if disability-adjusted life years could have been used in future papers to expand this research.

Is the work clearly and accurately presented and does it cite the current literature? Yes

Is the study design appropriate and is the work technically sound? Yes

Are sufficient details of methods and analysis provided to allow replication by others? 
Yes

If applicable, is the statistical analysis and its interpretation appropriate? Yes

Are all the source data underlying the results available to ensure full reproducibility? Yes

Are the conclusions drawn adequately supported by the results?

Yes

Competing Interests: No competing interests were disclosed.

Reviewer Expertise: Interaction of Tuberculosis and Diabetes, Health Systems Research, Diabetic epidemiology, Pscyhosocial Research

I confirm that I have read this submission and believe that I have an appropriate level of expertise to confirm that it is of an acceptable scientific standard.

Reviewer Report 17 January 2022

https://doi.org/10.5256/f1000research.78203.r119876

(C) 2022 Adil AA M. This is an open access peer review report distributed under the terms of the Creative Commons Attribution License, which permits unrestricted use, distribution, and reproduction in any medium, provided the original work is properly cited.

\section{Mohamed Adil AA}

Vinayaga Mission Research Foundation, Chennai, Tamil Nadu, India

The article highlights important areas in the arena of globalization and the spread of infectious diseases.

The article particularly looks into data from a number of countries globally, thus increasing the validity and reliability of the study across continents and also globally.

Could this study be replicated by using longitudinal data to establish causality and stronger inferences?

Do the path regression results provide more robust results than OLS analysis?

What was the main logic in choosing only a specific set of covariates and not all the possible covariates for tuberculosis?

This a good study and will help in addressing many lacunae in the area of global health research.

Is the work clearly and accurately presented and does it cite the current literature? 
Yes

Is the study design appropriate and is the work technically sound?

Yes

Are sufficient details of methods and analysis provided to allow replication by others? Yes

If applicable, is the statistical analysis and its interpretation appropriate?

Yes

Are all the source data underlying the results available to ensure full reproducibility? Yes

Are the conclusions drawn adequately supported by the results?

Yes

Competing Interests: No competing interests were disclosed.

Reviewer Expertise: Infectious Diseases, Biotechnology, Disease Transmission Dynamics

I confirm that I have read this submission and believe that I have an appropriate level of expertise to confirm that it is of an acceptable scientific standard.

Reviewer Report 14 January 2022

https://doi.org/10.5256/f1000research.78203.r102228

(C) 2022 Haksama S. This is an open access peer review report distributed under the terms of the Creative Commons Attribution License, which permits unrestricted use, distribution, and reproduction in any medium, provided the original work is properly cited.

\section{Setya Haksama}

Department of Health Administration and Policy, Public Health Faculty, Universitas Airlangga, Surabaya, Indonesia

1. All variables should be written clearly and systematically, first the independent variables should be described, then the dependent variables should be described.

2. Resources of data from World Bank was too old.

3. No data was obtained from 40 countries measured in relation to this research, there should be a ranking for each country that can indicate which countries have good scores and which countries have low scores.

Is the work clearly and accurately presented and does it cite the current literature? 
Yes

Is the study design appropriate and is the work technically sound?

Yes

Are sufficient details of methods and analysis provided to allow replication by others? Partly

If applicable, is the statistical analysis and its interpretation appropriate? Partly

Are all the source data underlying the results available to ensure full reproducibility? Yes

Are the conclusions drawn adequately supported by the results?

Partly

Competing Interests: No competing interests were disclosed.

Reviewer Expertise: Health Policy, Administration, and Disaster

I confirm that I have read this submission and believe that I have an appropriate level of expertise to confirm that it is of an acceptable scientific standard, however I have significant reservations, as outlined above.

\section{Author Response 14 Jan 2022}

Shyamkumar Sriram, Johns Hopkins Bloomberg School of Public Health, Baltimore, USA

Multiple data sources from multiple agencies were used. Data from the World Bank for specific years was used to match the data availability from other agencies. Data could not be obtained for the specific years for some of the countries. So they were not used for the research. Different variables have been adequately described in the paper.

Competing Interests: N/A 
The benefits of publishing with F1000Research:

- Your article is published within days, with no editorial bias

- You can publish traditional articles, null/negative results, case reports, data notes and more

- The peer review process is transparent and collaborative

- Your article is indexed in PubMed after passing peer review

- Dedicated customer support at every stage

For pre-submission enquiries, contact research@f1000.com 